\title{
Study of Nano-Granular Co-Zr-O Thin Films by Holography and HRTEM
}

\author{
Z. Liu ${ }^{*}$, D. Shindo ${ }^{*}$, S. Ohnuma ${ }^{* *}$ and H. Fujimori ${ }^{* *}$ \\ *Institute of Multidisciplinary Research for Advanced Materials, Tohoku University, 2-1-1 Katahira, \\ Aoba-ku, Sendai 980-8577, Japan \\ The Research Institute for Electric and Magnetic Materials, Sendai 982-0807, Japan
}

Developments in electric devices have led to an urgent request of higher frequency operation of magnetic devices. Thus higher magnetic anisotropy field $\left(\mathrm{H}_{\mathrm{k}}\right)$, saturation magnetization $\left(\mathrm{B}_{\mathrm{s}}\right)$ and electrical resistivity $(\rho)$ are the most important parameters for distinguished high frequency soft magnetic materials ${ }^{1}$ since the permeability $(\mu)$ is remarkably influenced by eddy current losses and the magnetic resonance at high frequency. Recently, such excellent magnetic properties have been obtained in the soft magnetic $\mathrm{Co}-\mathrm{Zr}-\mathrm{O}$ thin films ${ }^{2}$ which have a nano-granular structure. In the present work the magnetic structure and microstructure of $\mathrm{Co}-\mathrm{Zr}-\mathrm{O}$ films were evaluated by holography and HRTEM, respectively.

Three kinds of Co-Zr-O film with different compositions were prepared on water-cooled glass substrates (Corning $7059,0.5 \mathrm{~mm}$ in thickness) by a RF reactive magnetron sputtering in an $\mathrm{O}_{2}+\mathrm{Ar}$ atmosphere, using a Co-Zr alloy targets. The easy axes of the films were controlled by the magnetic field of permanent magnets. The details of the deposition condition were described elsewhere ${ }^{3}$. TEM samples were prepared by one-side grinding and ion-milling. JEM3000F (accelerating voltage $300 \mathrm{kV}$ ) equipped with a biprism was used for electron holography. JEM4000EX (400kV), JEM1250 $(1250 \mathrm{kV})$ and JEM2010F $(200 \mathrm{kV})$ were used for the investigation of the microstructures, Lorentz observations and microanalyses, respectively.

Figures $1 \mathrm{a}, 1 \mathrm{~b}$ and $1 \mathrm{c}$ are the Lorentz micrographs (under focus) of $\mathrm{Co}_{71.5} \mathrm{Zr}_{9.2} \mathrm{O}_{19.3}, \mathrm{Co}_{59.9} \mathrm{Zr}_{10.3} \mathrm{O}_{29.8}$ and $\mathrm{Co}_{52.9} \mathrm{Zr}_{12.0} \mathrm{O}_{35.1}$ thin films, respectively. The bright and dark lines indicated by arrows illustrate the magnetic domain walls. It can be seen that the domains of $\mathrm{Co}_{59.9} \mathrm{Zr}_{10.3} \mathrm{O}_{29.8}$, which has the highest $\mathrm{H}_{\mathrm{k}}(=11 \mathrm{kA} / \mathrm{m})$, are smaller than that of $\mathrm{Co}_{71.5} \mathrm{Zr}_{9.2} \mathrm{O}_{19.3}$, however domain walls can not be found in $\mathrm{Co}_{52.9} \mathrm{Zr}_{12.0} \mathrm{O}_{35.1}$. In order to have an intuitive observation of the magnetic structure, holograms were taken from these samples. Figures $2 \mathrm{a}, 2 \mathrm{~b}$ and $2 \mathrm{c}$ are the reconstructed phase images of $\mathrm{Co}_{71.5} \mathrm{Zr}_{9.2} \mathrm{O}_{19.3}, \mathrm{Co}_{59.9} \mathrm{Zr}_{10.3} \mathrm{O}_{29.8}$ and $\mathrm{Co}_{52.9} \mathrm{Zr}_{12.0} \mathrm{O}_{35.1}$, respectively. The contour lines show the magnetic flux and the arrows indicate its direction. Between two adjacent contour lines, there is a constant flux of $\mathrm{h} / \mathrm{e}\left(=4 \times 10^{-15} \mathrm{~Wb}\right)$ flows. It can be easily seen that $\mathrm{Co}_{59.9} \mathrm{Zr}_{10.3} \mathrm{O}_{29.8}$ shows clear magnetic domains, however $\mathrm{Co}_{52.9} \mathrm{Zr}_{12.0} \mathrm{O}_{35.1}$ shows no distinct domains. The HRTEM images of these three kinds of Co-Zr-O films are shown in Figure 3. All of these films have a nano-granular structure. Through the diffraction patterns and the microanalysis results, it is shown that the metallic particles are mostly pure Co although it can not exclude the possibility that a little bit $\mathrm{Zr}$ would be contained in the Co grains. The amorphous matrix is zirconium oxide and it also seems that there are some $\mathrm{Co}$ atoms in the matrix which indicates to form $\mathrm{Co}-\mathrm{Zr}$ amorphous structure. Although the particle sizes of $\mathrm{Co}$ are about a few nanometers for these three samples, $\mathrm{Co}_{71.5} \mathrm{Zr}_{9.2} \mathrm{O}_{19.3}$ shows not only the biggest size but also the highest density of Co particles. This result exactly explains why $\mathrm{Co}_{71.5} \mathrm{Zr}_{9.2} \mathrm{O}_{19.3}$ has the highest $\mathrm{B}_{\mathrm{s}}(=12 \mathrm{kG})$ among these three samples. On the other hand, $\mathrm{Co}_{52.9} \mathrm{Zr}_{12.0} \mathrm{O}_{35.1}$, in which the Co particles are magnetically isolated, is in super-paramagnetic state.

References

[1]. A. Hosono and Y. Shimada, J. Magn. Soc. Jpn., 12 (1988) 295.

[2]. S. Ohnuma et al., IEEE Trans. Mag., 37 (2001) 2251.

[3]. S. Ohnuma et al., J. Appl. Phys., 79 (1996) 5130.

[4]. The author thanks Dr. T. Ohsuna for his software on phase reconstruction and Prof. K. Hiraga and T. Oikawa for valuable discussions. 

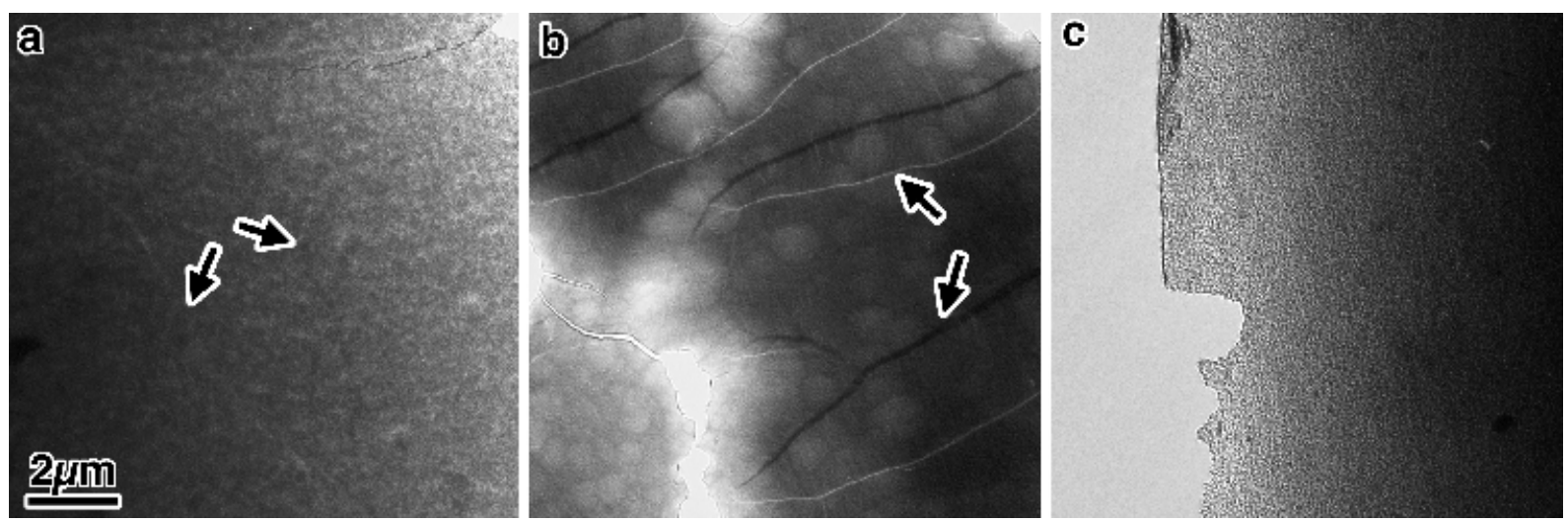

Figure 1: Lorentz micrographs (under focus) of $\mathrm{Co}_{71.5} \mathrm{Zr}_{9.2} \mathrm{O}_{19.3}$ (a), $\mathrm{Co}_{59.9} \mathrm{Zr}_{10.3} \mathrm{O}_{29.8}$ (b) and $\mathrm{Co}_{52.9} \mathrm{Zr}_{12.0} \mathrm{O}_{35.1}$ (c) thin films.

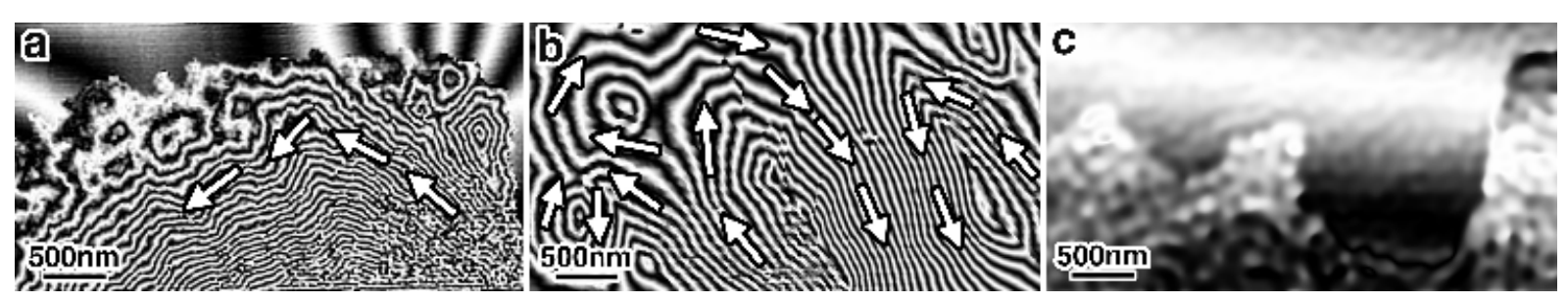

Figure 2: Reconstructed phase images of $\mathrm{Co}_{71.5} \mathrm{Zr}_{9.2} \mathrm{O}_{19.3}$ (a), $\mathrm{Co}_{59.9} \mathrm{Zr}_{10.3} \mathrm{O}_{29.8}$ (b) and $\mathrm{Co}_{52.9} \mathrm{Zr}_{12.0} \mathrm{O}_{35.1}$ (c).
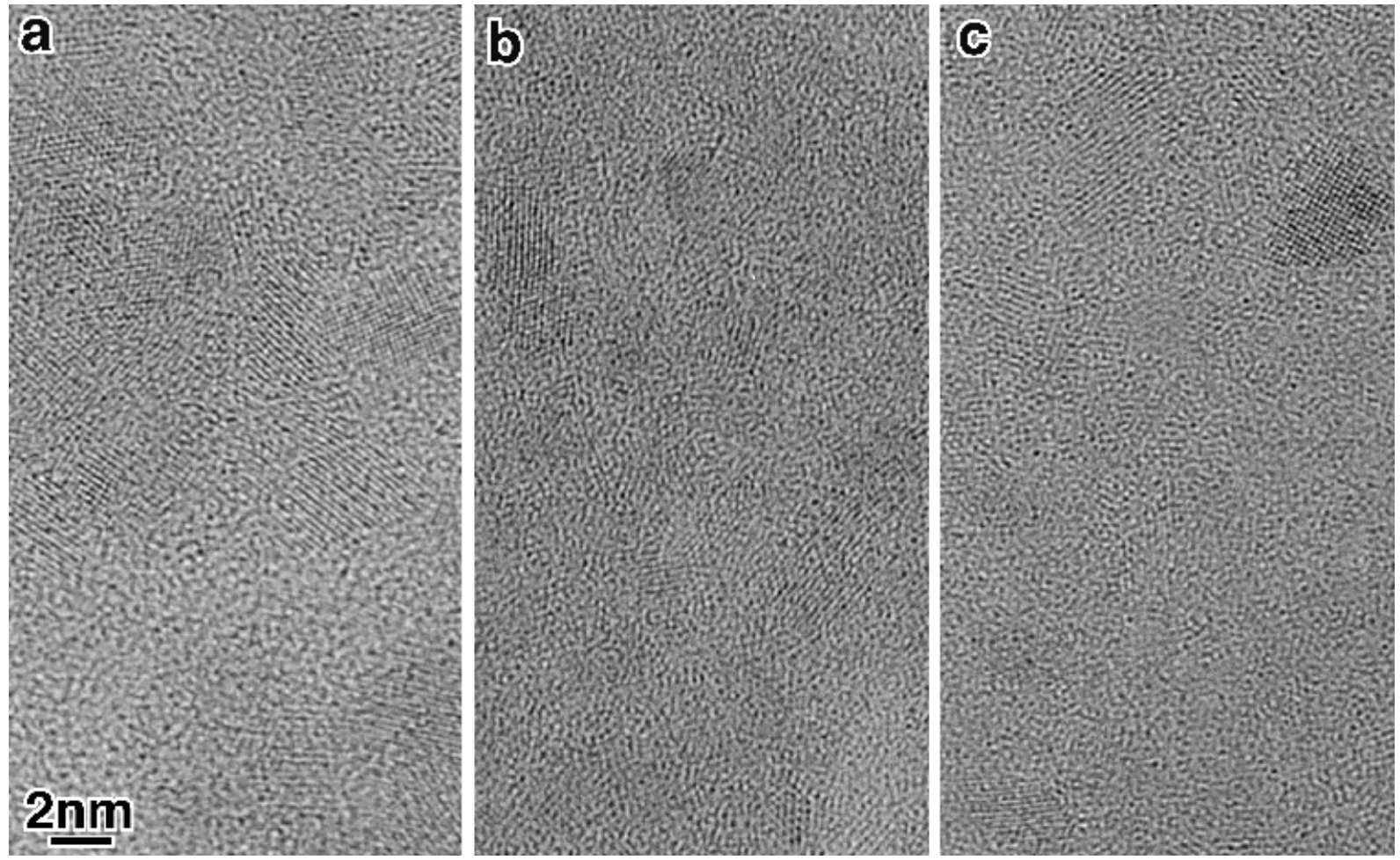

Figure 3: HRTEM images of $\mathrm{Co}_{71.5} \mathrm{Zr}_{9.2} \mathrm{O}_{19.3}$ (a), $\mathrm{Co}_{59.9} \mathrm{Zr}_{10.3} \mathrm{O}_{29.8}$ (b) and $\mathrm{Co}_{52.9} \mathrm{Zr}_{12.0} \mathrm{O}_{35.1}$ (c). 